\title{
Creative Development as Acquired Expertise: Theoretical Issues and an Empirical Test
}

\author{
Dean Keith Simonton
}

University of California, Davis

\begin{abstract}
Although outstanding creativity has been viewed as an acquired expertise, creative development might operate differently than occurs in sports, games, and music performance. To test the creative-expertise hypothesis, the careers of 59 classical composers were examined according to the differential aesthetic success of their 911 operas. The potential predictors were seven measures of domain-relevant experience: cumulative years (since first operas, first compositions, and first lessons) and cumulative products (genre-specific operas, all operas, all vocal compositions, and all compositions). The nonmonotonic longitudinal trends and the relative explanatory power of the expertise-acquisition measures indicate that complex specialization ("overtraining') and versatility ("cross-training') effects may determine creative development across the life span. The broader implications of the findings are then discussed. (c) 2000 Academic Press
\end{abstract}

Keywords: creative development, acquired expertise, overtraining, cross-training, aesthetic success, classical music.

What is the developmental basis for world-class success in a culturally valued achievement domain? For example, how do certain individuals become able to earn Nobel prizes for literary creations or scientific discoveries, gain first prizes at international piano competitions, win gold medals at the Olympics, or emerge victorious at chess championships? Although such exceptional achievements are necessarily rare with respect to the human population, it is also clear that we cannot completely understand the origins of individual differences without explaining how some people develop extraordinary levels of performance and influence. One of the oldest explanations is that such extreme attainments reflect innate abilities or special talents (Winner, 1996). A classic instance is Galton's (1869) argument that heredity provides the primary basis for distinction in domains as diverse as science,

I thank Robert J. Sternberg, Jim Cassandro, and James Kaufman for their comments on an earlier draft of the manuscript. This article is based on a paper read at a symposium held at the meeting of the American Psychological Association, Boston, 1999.

Address correspondence and reprint requests to Dean Keith Simonton, Department of Psychology, One Shields Avenue, University of California, Davis, California 95616-8686. E-mail: dksimonton@ucdavis.edu. 
literature, music, art, religion, politics, war, and sports (see also Bramwell, 1948). Nevertheless, although hereditarian accounts may still account for some proportion of the individual-difference variance, it remains highly likely that environmental factors play a much more powerful role (Simonton, 1999b). Specifically, evidence has been growing that the primary foundation of exceptional performance may be what Ericsson and his colleagues have called deliberate practice (Ericsson \& Charness, 1994; Ericsson, Krampe, \& Tesch-Römer, 1993). This evidence takes the form of extremely thorough studies of development in standard talent domains such as music performance, chess, and sports (Bloom, 1985; Csikszentmihalyi, Rathunde, \& Whalen, 1993; Ericsson, 1996b; Howe, Davidson, \& Sloboda, 1998). Yet there also exists evidence that exceptional leadership may have a comparable foundation. For example, one of the best predictors of a military leader's tactical success is the amount of prior battle experience he has relative to his opponent (Simonton, 1980a).

Therefore, it seems reasonable to argue that the same principles of expertise acquisition may apply equally well to domains of creative achievement (Ericsson, 1996a; Hayes, 1989; Ohlsson, 1992). Even the most awesome creative geniuses may have merely studied harder and longer than their less remarkable colleagues. As empirical support, researchers have spoken frequently of the 10-year rule, which asserts that it takes about a decade of intense study and practice to acquire world-class proficiency in any domain of achievement (Ericsson, Krampe, \& Tesch-Römer, 1993; see also Simon \& Chase, 1973). For example, Hayes (1989) conducted an investigation of 76 classical composers that showed how the typical creator was often composing for a full decade before the first genuine masterwork appeared (see also Gardner, 1993; Simonton, 1991b). One attractive feature of this expertiseacquisition explanation is its egalitarian position toward the development of creative potential. Individual differences in creative achievements may be ascribed largely, if not entirely, to the amount of effort and time a person devotes to domain mastery (Ericsson, Krampe, \& Tesch-Römer, 1993). The implication is that genius is self-made, not inborn.

Nonetheless, certain considerations also suggest that outstanding creativity may require something more than the straightforward acquisition of domain expertise. The problems with the creative-expertise hypothesis are both empirical and theoretical.

\section{Empirical Problems with the Creative-Expertise Hypothesis}

Past research has established several results that do not seem very consistent with the notion that exceptional creators are merely extreme experts in their chosen domains (Simonton, 1996). The following three sets of findings are especially problematic:

1. Numerous individual-difference variables appear to separate those who 
merely master domain-specific skills and knowledge from those who actually make creative contributions (Feist, 1998; Simonton, 1999a; Sternberg \& Lubart, 1995). For example, many personality studies have indicated that those who are considered notable creators in a domain have identifiably different character traits than do domain experts (i.e., persons who are otherwise comparable in training, experience, and professional standing; see, e.g., Barron, 1969; Helson \& Crutchfield, 1970; MacKinnon, 1978; Rostan, 1994). Among the distinguishing attributes are the creator's greater inclination toward nonconformity, unconventionality, independence, openness to experience, ego strength, aggressiveness, risk taking, introversion, and even psychopathology. Perhaps the most provocative individual-difference factor is the tendency for highly influential creators to have broader interests and greater versatility than their noncreative colleagues (Gough, 1976; Manis, 1951; Raskin, 1936; Simon, 1974; Simonton, 1976; White, 1931). If exceptional creativity tends to be associated with the acquisition of mastery in more than one domain, there may be gains from "cross-training'" in creative domains that may not have equivalents in chess, sports, or music performance.

2. The developmental antecedents, including domain-relevant experiences, may differ for experts and creators. For instance, one investigation into the differential success of 120 classical composers discovered that the most productive and eminent (a) were engaged in music training for fewer years before they began serious composition and (b) were actively composing works for fewer years before they began to make their first lasting contributions to the repertoire (Simonton, 1991b). These two relations suggest that the most prolific and acclaimed composers required less time to attain the mastery necessary for creative achievement. Comparable results have been found for other domains of creativity (Cox, 1926; Raskin, 1936), including the sciences (e.g., Roe, 1952; Simonton, 1991a, 1992; Zuckerman, 1977). Major creators appear to require domain-relevant expertise less time than average. In addition, research has found that the relation between formal training and creative achievement often runs counter to expectation. In particular, exceptional creativity can sometimes be a curvilinear, inverted-U function of education or training (Simonton, 1983, 1984a). Sometimes, too, the most innovative individuals are those whose training is marginal rather than central to the field of major achievement (Hudson \& Jacot, 1986; Kuhn, 1970; Simonton, 1984c). The history of psychology includes such examples as Freud, Pavlov, Piaget, and B. F. Skinner. These findings imply that excessive domain specialization can undermine creative development.

3. The characteristics of creative careers in adulthood seem to be inconsistent with what might be predicted according to a simple expertise-acquisition process (Simonton, 1988a). In the first place, creative productivity only increases at the beginning of the career, whereas after attaining the career peak 
output tends to decline (e.g., Dennis, 1966; Lehman, 1953, 1962; Simonton, 1984b, 1989a). Such a negative age trend is not easily explained with the expertise framework. For example, it is not always apparent that such decrements can be ascribed to the obsolescence of domain-relevant knowledge and skills (e.g., McDowell, 1982). Nor is it clear that such declines can be completely attributed to the cognitive and physiological repercussions of aging (Simonton, 1988a, 1997), unlike what probably holds for such achievement domains as chess and sports where age decrements also occur (Elo, 1965; Schulz \& Curnow, 1988; cf. Krampe \& Ericsson, 1996). Even more important, the career of the typical creator consists of a chaotic sequence of hits and misses, of successes and failures. A universally acclaimed masterpiece might be followed immediately after by a widely criticized or ignored attempt (e.g., Shakespeare's plays; Simonton, 1986b). In fact, the ratio of hits to total attempts does not increase over the course of the career, but rather tends to fluctuate randomly (e.g., Quételet, 1835/1968; Simonton, 1977a, 1985, 1997). Hence, creators do not seem able to acquire the expertise necessary to increase their odds of success.

In sum, the character, development, and adulthood career of the domain creator seems distinguishable from what characterizes the domain expert.

\section{Theoretical Problems with the Creative-Expertise Hypothesis}

It has been argued that the expertise behind creativity may involve very different processes than those that underlie exceptional performance in other domains (Simonton, 1999a). Consider the following five distinctive aspects of creative achievement:

1. A gymnast who repeats the same flawless performance in competition after competition will be considered remarkable, whereas a writer who writes the same novel over and over would be considered less than a hack. By definition, creative products must be original, novel, or surprising. Mere repetition of previous work is necessarily disqualified as creativity (Martindale, 1990). This requirement would seem to undermine the automatization of information processing that appears so highly characteristic of genuine expertise (Frensch \& Sternberg, 1989).

2. At the same time, the creative individual must not produce work that is excessively original, for the product may then become incomprehensible, even to a degree that it provokes unpleasant emotional arousal (Berlyne, 1971). For example, empirical studies have found that the impact of an artistic product is often a curvilinear, inverted- $U$ function of originality and similar aesthetic features (e.g., Kammann, 1966; Simonton, 1980b, 1986a, 1987; Steck \& Machotka, 1975; Vitz, 1964). As a consequence, creators must somehow identify just the right amount of originality that will maximize success - a far more difficult task than simply executing some well-learned skill faster, farther, higher, or more precisely. 
3. This foregoing task is rendered all the more complicated by the fact that most creative products are defined by a larger number of dimensions than is the likely case for simpler areas of expert performance (Berlyne, 1971; Martindale et al., 1988; Shadish, 1989; Sternberg \& Gordeeva, 1996). A painting, for example, is characterized by diverse aspects of subject, size, form, balance, color, line, and brushwork (Arnheim, 1971). Moreover, these various factors may contribute to a work's ultimate success by nonlinear and nonadditive effects (see, e.g., Martindale \& Moore, 1989; Simonton, 1980b, $1990,1999 b)$. It is possible that the creator can only find the optimal configuration after considerable trial and error.

4. Such trial-and-error learning would be rendered difficult by inherent limits to human information processing (Faust, 1984; Fiske \& Taylor, 1991; Kahneman, Slovic, \& Tversky, 1982; Meehl, 1954). Persons are not especially adept at inferring regularities that contain many variables that operate according to interactive and curvilinear functions, especially when these functions are probabilistic rather than deterministic.

5. Unlike the case for many skill domains, the creator seldom receives the most informative environmental feedback (Simonton, 1999a). The reactions are largely more global (success or failure) than highly differentiated, making it difficult for creators to discern the precise reasons for the uneven nature of their output. Even more problematic, the reactions usually lack consensus and temporal stability (see, e.g., Cicchetti, 1991; Cole, 1983; Lindsey, 1988). Critics may differ among themselves and with audiences; a work might be an instantaneous success only to decline in popularity as a mere fad, whereas another work might be a sleeper that slowly accumulates aficionados. Indeed, many theories of artistic and scientific change suggest that the standards by which a work is judged are constantly evolving rather than stable (e.g., Kuhn, 1970; Martindale, 1990; Sorokin, 1937-1941). What at one moment might have been considered avant-garde or revolutionary may later be viewed as passé or reactionary.

Taken as a whole, the foregoing features should make it extremely difficult if not impossible for creative individuals to acquire the mastery necessary for consistent success in their chosen domain. This would be especially true in those domains in which (a) the pressure for both originality and intelligibility is intense, (b) the products are invariably multidimensional and configurational, (c) the output rate for those products must be correspondingly low, and (d) the reactions from the public, critics, and colleagues are mostly undifferentiated, inconsistent, and unstable.

\section{Three Critical Questions}

The doubts raised by the above empirical and theoretical considerations suggest the need to scrutinize the true extent that creativity can be considered an acquired expertise. Accordingly, the current investigation gauges the part 
accumulated experience plays in creative performance. Specifically, this study addresses three critical questions:

1. What domain-specific experiences are most predictive of creative performance? Past research on creative development has almost exclusively used cumulative years of experience as the predictor variable, including the number of years since (a) formal training began, (b) the highest degree was attained, or (c) the first product appeared (e.g., Hayes, 1989; Lyons, 1968; Simonton, 1992). Yet studies of expertise acquisition in sports, games, and music suggest that such measures provide very poor predictors of accomplishment level (Ericsson, 1996a). Instead, it is the actual amount of time devoted to deliberate practice that provides the best prediction of attainment. Of course, creativity functions in a different manner; once careers begin creators do not "practice" their expertise in the same fashion as a champion gymnast, chess player, or violin virtuoso. Nonetheless, the output of products may be considered the closest parallel. If so, then cumulative counts of products should provide superior predictors of a given product's creative impact. There has been only one prior investigation using this type of measure, and it obtained inconclusive results (Simonton, 1995). Specifically, the order in which a symphony was written did not predict its popularity in the repertoire nor its rating for aesthetic significance and actually had a negative association with its accessibility to concert audiences. Even so, because these works came from the pens of prolific symphonists, the measure of cumulative symphonic products may have had insufficient variance to provide a conclusive response to this particular question.

2. What is the degree of domain specificity in the experience-performance association? For example, is success as a poet enhanced by extensive experience writing prose? Or would the poet have gained more from having spent more time writing poetry instead? In more general terms, to what extent does the creative individual benefit from the intellectual analog of crosstraining? The broad interests and versatility of exceptional creators indicate that expertise must be wide and diverse rather than narrow and specialized. In fact, some discussions of the creative process have underlined the importance of cross-talk between separate projects, including projects that may have no apparent connection with each other (Gruber, 1974; Hargens, 1978; RootBernstein, Bernstein, \& Garnier, 1993; Simon, 1974; Tweney, 1990). These work habits enable the creator to view problems from multiple perspectives, sometimes finding that the solution to one problem can provide the solution to another, seemingly different problem. Such information-processing flexibility tends to be alien to what normally operates in the execution of a bona fide expertise (Frensch \& Sternberg, 1989).

3. What developmental trend best describes the experience-performance curve? Is the success of a creative product a positive monotonic function of cumulative experience within the product's domain? If the expertise-acquisi- 
tion explanation is justified, the creativity displayed by an individual should not decrease as a function of domain-relevant experience (once extraneous factors are controlled). It should be stressed that this positive "practicemakes-perfect" effect does not have to be linear (Ericsson, Krampe, \& Tesch-Römer, 1993). On the contrary, it could be that there eventually intrudes a "law of diminishing returns," whereby the benefits of increased experience decline in a decelerating curve (see, e.g., Ohlsson, 1992). If, on the other hand, the relation were better described by a single-peaked function, then creativity would seem to be undermined by a kind of intellectual "overtraining', or excessive specialization. Experimental research on problem solving has long noted how "functional fixedness" can prevent a person from attaining that insight essential for the problem's solution (Seifert, Meyer, Davidson, Patalano, \& Yaniv, 1995; Smith, 1995). In fact, it may be that intellectual cross-training may have the advantageous function of mitigating the negative effects of overtraining.

It appears that no published study has explicitly addressed these three critical questions. Yet, curiously, the development of creative expertise may be more open to scientific inquiry than is expertise development in talent domains like sports, games, and performance. Inquiries into the latter domains must either conduct difficult longitudinal studies (e.g., Subotnik \& Arnold, 1994) or else depend on the retrospective reports of the participants, their parents, and their teachers or coaches (e.g., Ericsson, 1996b). In contrast, almost all of the creator's expertise development is extremely well documented. For instance, archival data are readily available for counting the number of years that have passed since works in a particular genre were first produced or for tabulating the number of published products of a particular type. Furthermore, in the domain of creative expertise it is easy to study individuals who have completed their careers, enabling the inquiry to extend across the entire human life span (e.g., Dennis, 1966; Simonton, 1977c). Indeed, an accurate evaluation of expertise acquisition must include the very last works a creator contributes to his or her domain, for these may represent the very acme of their creative careers (Simonton, 1989b). These methodological advantages make the current inquiry all the more urgent. Not only are the questions critical to our understanding of creative development, but in addition these questions can be addressed with sufficient scientific rigor.

\section{The Research Site: The Operatic Output of Classical Composers}

It is now necessary to identify a representative collection of products that can be said to gauge an individual's creative performance at a given time in his or her career. Although almost any creative domain might be studied in the arts and sciences, I have selected opera. Operatic products have six assets that make them suitable research sites for addressing the three critical questions: 
1. The great cost of operatic productions puts composers under intense pressure to create works that are both highly novel and very accessible. Operas that fail to attain either of these two ends will run for a few nights and then be pulled off the stage, with no benefit to the composer's pocketbook or reputation. The composer is much more likely to endeavor to render each operatic product a pièce de résistance of the career rather than throw something together hastily as a casual pièce d'occasion.

2 . Because operas are ordinarily produced shortly after their composition, the feedback from audiences is immediate and highly public-especially since the composer almost always attends the premiere. This feedback is also largely global (standing ovations versus catcalls and boos), often inconsistent (from one opera house to another), and frequently unstable (owing to changes in operatic fashions). Complicating matters all the more is the feedback received at the hands of critics in various newspapers and journals throughout the opera world.

3. Operas come in different genres, such as grand opera, music drama, opera buffa, and operetta. This permits a closer examination of the degree of expertise specificity (e.g., whether the impact of a given opera is dependent primarily on prior experience with opera in the same genre).

4. The operatic form is among the most complex of all artistic creations. A competent composer must often be able to visualize and realize a work that incorporates: instrumental music (overture, interludes, descriptive scenes, and ballet), vocal music (arias, ensembles, and chorus), drama (dialogue, characterization, and plot development), costumes, scenery, and special effects (when essential to successful presentation), and choreography (especially in grand opera). The multidimensional nature of the form means that an effective opera must depend on the acquisition of several distinct kinds of expertise, each contingent on its own set of preparatory experiences (e.g., instrumental versus vocal music).

5. The complex, ambitious, and costly nature of the form also means that composers cannot go through too many trial-and-error cycles. Although a composer like Rossini could sometimes compose as many as two operas per year, most composers require years to complete a single work, even when they are creating nothing else besides opera at the time (e.g., Wagner and Verdi).

6. Operatic composers differ tremendously in their compositional versatility. At one extreme are those who compose almost exclusively operas, often even restricting their output to just a few operatic genre (e.g., Lehár and Puccini). At the other extreme are those whose primary compositional creativity occurs in other forms of classical music, including that purely instrumental (e.g., Mozart, Debussy, and Tchaikovsky). This range permits the determination of whether these extraoperatic experience makes a positive contribution to the quality of the works a composer does create for the opera house. 


\section{METHODS}

\section{Sample: 911 Operas}

Although thousands of composers have written operas, only a small proportion have ever displayed the expertise necessary to create an opera that became a lasting success. The sample of operas was accordingly defined as all of the extant works produced by every composer who is credited with at least one opera that became part of the standard repertoire. To be considered standard repertoire, an opera had to fulfill the following five requirements: (a) recorded at least twice in any of the regular recording formats from 78 rpm to compact disk, as noted in 10 catalogs or guides to recordings (e.g., Bontinck-Küffel, 1974; Celletti, 1976); (b) granted plot summaries in at least two of six books containing or featuring synopses (e.g., Harewood, 1994; Holden, Kennon, \& Walsh, 1993); (c) received separate entries in at least two of five one-volume encyclopedias or dictionaries of opera (e.g., Hamilton, 1987; Osborne, 1983); (d) mentioned in at least two of five histories of opera (e.g., Grout, 1988; Parker, 1994); and (e) performed in the 20th century in at least 2 of 10 major opera houses, at least one of which is located outside the nation of origin (using, e.g., Bauer, 1952; Pokorovsky \& Grigorovich, 1979; Walsh, 1986). Given this criterion, 59 composers could be credited with at least one successful opera. ${ }^{1}$ These composers produced a total of 911 extant operas, the latter figure representing the sample size for this inquiry. Of these 911 works, 139 remain a part of the standard repertoire (albeit they still vary considerably in ultimate success). The remaining works, in contrast, range from the also-rans, which are recorded, performed, and discussed only occasionally, down to those works that have been completely forgotten, notwithstanding the fact that they were written by well-known composers who had sufficient expertise sometime during their careers to produce at least one operatic "hit."

${ }^{1}$ The 59 composers are (with birth/death dates and their extant opera count): Bartok 18811945, 1; Beethoven 1770-1827, 1; Bellini 1801-1835, 10; Berg 1885-1935, 2; Berlioz 18031869, 5; Bizet 1838-1875, 7; Boito 1842-1918, 2; Borodin 1833-1877, 1; Britten 19131976, 16; Charpentier 1860-1956, 4; Cherubini 1760-1842, 30; Cilèa 1866-1950, 6; Debussy 1862-1918, 3; Delibes 1836-1891, 22; Donizetti 1797-1848, 69; de Falla 1876-1946, 4; Flotow 1812-1883, 31; Gershwin 1898-1937, 21; Giordano 1867-1948, 12; Glinka 18041857, 2; Gluck 1714-1787, 32; Gounod 1818-1893, 12; Handel 1655-1759, 44; Humperdinck 1854-1921, 10; Janácek 1854-1924, 9; Lehár 1870-1948, 35; Leoncavallo 1857-1919, 20; Mascagni 1863-1945, 17; Massenet 1842-1912, 31; Menotti 1911- , 25; Meyerbeer 17911864, 16; Montemezzi 1875-1952, 7; Monteverdi 1567-1643, 11; Mozart 1756-1791, 20; Mussorgsky 1839-1881, 4; Nicolai 1810-1849, 4; Offenbach 1819-1880, 97; Ponchielli 1834-1886, 10; Poulenc 1899-1963, 4; Prokofiev 1891-1953, 8; Puccini 1858-1924, 12; Purcell 1659-1695, 6; Ravel 1875-1937, 2; Rimsky-Korsakov 1844-1908, 15; Rossini 17921868, 38; Saint-Saëns 1835-1921, 12; Shostakovich 1906-1975, 3; Smetana 1824-1884, 8; J. Strauss 1825-1899, 16; R. Strauss 1864-1949, 16; Stravinsky 1882-1971, 9; Tchaikovsky 1840-1893, 8; Thomas 1811-1896, 20; Verdi 1813-1901, 26; Wagner 1813-1883, 13; Walton 1902-1983, 2; Weber 1786-1826, 8; Weill 1900-1950, 21; Zandonai 1883-1944, 11. 


\section{Independent Variables: Expertise Acquisition}

The accumulation of domain-relevant skills and knowledge was measured by two sets of measures:

1. Cumulative years: Three measures gauged how long the composer had been accumulating musical experience at the time a particular sampled opera was composed (in all cases counting all years between the onset of a given form of experience and the year of composition). In decreasing order of domain specificity, these are the years since first opera, years since first music composition, and years since first music lessons. The first measure was based on the standard reference books for opera (e.g., Sadie, 1996), the second on the chronological listings of major compositions in Gilder and Port (1978), and the third on the measures compiled for an earlier study of 120 classical composers (Simonton, 1991b).

2. Cumulative compositions: Four measures assessed how many works a composer had to his credit at the time a given opera was composed (including the opera itself in the count). Again in decreasing order of domain specificity, these are the number of genre-specific operas, the number of operas regardless of their genre, the number of vocal compositions of all kinds, and the number of total compositions of all types. The first count only included operas in precisely the same genre, whereas the second included all operas no matter what their genre. ${ }^{2}$ Vocal compositions included songs, cantatas, masses, oratorios, and various other solo and choral works. The first two measures were based on standard opera reference books (e.g., Sadie, 1996), whereas the last two added the corresponding works listed in Gilder and Port (1978).

Table 1 gives the correlations and descriptive statistics for these seven measures. The three cumulative years indicators correlate very highly with each other and so do the indicators of all operas and all vocal works. Other correlations are more modest, especially those between the cumulative years and the cumulative composition measures. The lowest correlation is that between the number of years composing and the number of genre-specific operas composed. The descriptive statistics, and especially the ranges, show that the 911 operas vary greatly in the amount of prior experience the com-

${ }^{2}$ The terms for operatic genre are both highly varied and multilingual-over a 100 terms altogether were applied to the 911 operas. This is true even though for any given composer, the number of distinct terms is rather more restricted. To give something of the range, the following terms can be considered representative of the possibilities: azione storica, burlesque, children's opera, church opera, comic opera, dramma giocoso, fairy-tale opera, farsa, festa teatrale, folk opera, grand opera, heroic opera, intermezzo, little opera, lyric opera, madrigal ballet, melodrama, music drama, musical comedy, musical play, novelistic scenes, opera buffa, operetta, pantomime, poem lyrique, puppet opera, revue, romantic opera, scena lirica, semi-opera, singspiel, television opera, tragedia, vaudville, and zarzuela. Within each composer, operas made up separate cumulative counts when they had strictly distinct terms. For instance, opera semiseria was tabulated separately from opera seria. 


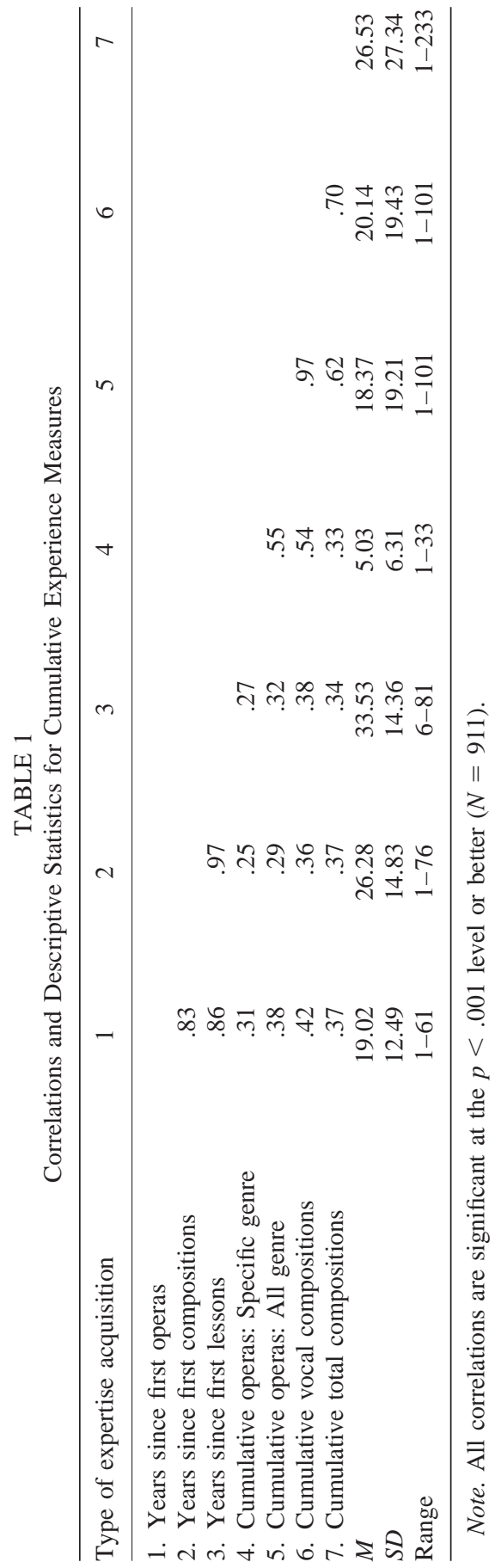


poser may bring to bear on a particular work. Thus, as many as 61 years may have transpired since a composer created his first composition, and a given opera may have been the composer's 233rd work. The truly life-span developmental range of the current inquiry is made all the more apparent by these additional facts: The first music lessons began as early as age 2 $(M=8.71, S D=3.50$, maximum $=21)$, the first compositions appeared as early as age $4(M=15.27, S D=5.45$, maximum $=27)$, and the first operas were composed as early as age $11(M=27.56, S D=8.54$, maximum $=54)$, while, at the other extreme, one opera was actually created when its composer was 84 years old.

The above seven measures are designed to assess linear effects. However, two other types of longitudinal trends are possible. First, it is conceivable that the best-fitting function might be described by a decelerating curve (the law of diminishing returns). To accommodate this possibility, the seven indicators were also log-transformed. Second, because the longitudinal function may be nonmonotonic, each of the seven original measures was placed in mean-deviation form and then squared to produce a set of linear and quadratic terms (Darlington, 1990).

\section{Dependent Variables: Log-Transformed and Residualized Aesthetic Success}

The differential merit of the 911 operas was gauged by a composite measure consisting of the following seven sets of indicators: (a) the number of times an opera was recorded according to eight catalogues of recordings (e.g., Blyth, 1994; Greenfield, Layton, \& March, 1993); (b) the number of video recordings according to three guides to opera on video (e.g., Almquist, 1993; Rohan, 1994); (c) the number of times an opera was performed in 10 of the world's major opera houses (e.g., Bloomfield, 1978; Rosenthal, 1958; Fawkes, 1986); (d) the number of lines devoted to each opera according to three separate opera dictionaries (e.g., Hamilton, 1990); (e) the number of pages devoted to each opera according to five histories of opera (e.g., Headington, Westbrook, \& Barfoot, 1987; Sadie, 1989); (f) rank-category measures derived from 5 reference works (e.g., Gammond, 1979); and (g) a single tabulation of the number of times the opera was explicitly identified as a major work in four separate reference works (Digaetani, 1986; Forman, 1994; Freeman, 1984; Simon, 1989). Details of the sources and definitions may be found in Simonton (1998), who also demonstrated that current success correlates positively with how well the opera was received by contemporary audiences (for a subset of 496 operas for which the latter information was available). Principal components analysis showed that the measures are essentially unidimensional, the first component explaining $63 \%$ of the total variance, and the factor loadings ranging between .44 and .96 (see Simonton, $1991 \mathrm{c}$, for the generality of this conclusion). In fact, the internal-consistency reliability coefficient for the resulting 35 -item composite index is $.86(M=$ 
$69.28, S D=185.24$, range $=0$ to 1726$)$. Because the distribution of scores was highly skewed right (skewness $=4.87$ and kurtosis $=28.41$ ), it was subjected to a logarithmic transformation $(M=2.08, S D=2.20$, range $=$ -0.69 to 7.45 , skewness $=0.33$, and kurtosis $=-0.98$ ).

Besides this log-transformed measure of aesthetic success, an alternative measure was defined as the residual of a multiple regression equation that incorporated 11 control variables. These variables were defined as follows:

1. Prior research has demonstrated that the success of aesthetic products tends to be a curvilinear, inverted-U function of the creator's age (Simonton, 1980b, 1986b). Therefore, the composer's age at the time of an opera's creation was put in mean-deviation form to generate a linear term, and then the latter was squared to generate a quadratic term (Darlington, 1990). Removal of this source of longitudinal variance ensures that effects ascribed to cumulative experience are not merely due to age effects independent of acquired expertise. That is, if the developmental curves still display negative slopes after partialing out chronological age, then these decrements cannot be easily dismissed as the consequence of slower reaction times or decreased physical health. Instead, they may betray the effects of overtraining or overspecialization.

2. Sometimes an opera is composed under conditions that might reflect its ultimate aesthetic impact. In particular, zero-one dummy variables were defined to accommodate the following circumstances: (a) whether the opera was left incomplete by the composer and thus finished by someone else (2\%); (b) whether the opera was a collaborative effort involving two or more composers $(2 \%)$, (c) whether the opera was composed in the creator's native language $(65 \%)$; and (d) whether the opera had undergone one or more revisions since its first production $(21 \%)$. These particular controls were selected because they are the best documented in the reference sources and because they are likely to have repercussions for a work's aesthetic success.

3. Fully $88 \%$ of the 911 works have libretti in Italian (36\%), French (32\%), German (15\%), and Russian (5\%). Therefore, zero-one dummy variables for each of these languages, leaving operas in other languages to define the control group (i.e., the regression intercept). For the most part, this variable controls for nation of origin as well. With the exception of a few cosmopolitan creators, such as Handel, Gluck, and Mozart, most composers wrote the bulk of their operas in their native tongue.

4. The 911 operas were composed between 1607 and 1988, an interval of 382 years. Because previous studies have found significant trends in various measures of aesthetic success (e.g., Simonton, 1980b), the date of composition was introduced as a control variable. This date was used rather than performance date because the focus is on how much expertise its creator had acquired at the time of composition (cf. Simonton, 1998). However, because performance date correlates .99 with composition date, the choice between the two makes no difference in the empirical findings. 
When the log-transformed measure of aesthetic success was regressed on the above 11 variables, $19 \%$ of the variance was explained $\left(R^{2}=.19\right)$. Almost all of the predictors were found to make significant contributions to the explained variance: linear age $(b=0.0243, \beta=.15, t=4.34, p<.001)$, quadratic age $(b=-0.0008, \beta=-.08, t=2.56, p<.05)$, collaborative work $(b=1.66, \beta=-.09, t=3.04, p<.001)$, native language $(b=1.12$, $\beta=.24, t=7.17, p<.001)$, revision $(b=0.62, \beta=.16, t=5.35, p<$ $.001)$, French $(b=-1.17, \beta=-.25, t=4.99, p<.001)$, and the date of composition $(b=-0.003, \beta=-.09, t=2.49, p<.05)$. Stated in words, the differential success of the 911 operas is an inverted-backwards-J function of age (with a peak at age 57), a negative function of composition date, and is higher for native-language and revised operas but lower for French and collaborative operas. There were also marginally significant effects for the Russian (positive, $p=.055$ ) and German (negative, $p=.094$ ) dummy variables. The prediction errors of this regression equation were then used to define the residualized measure of aesthetic success. The correlations of these residualized scores with the expertise-acquisition measures will accordingly constitute semi-partial correlations (Darlington, 1990).

Fortunately, because the log-transformed and residualized measures correlate $.90(p<.001)$, the results are quite similar across the various data analyses. $^{3}$ The main difference is that the effect sizes and corresponding significance levels are usually smaller for the residualized measures.

\section{RESULTS}

Before presenting the findings, it is first necessary to address a critical methodological issue raised by these data: What is the most appropriate way to determine whether certain associations are statistically significant? A universally accepted answer to this question is probably unattainable. Not only is the significance-test controversy one of the oldest in the behavioral sciences, but also the debate seems hardly closer to resolution than it was 30 years ago (Harlow, Mulaik, \& Steiger, 1997; Morrison \& Kenkel, 1970). The controversy centers on the relative scientific utility of conventional significance tests (inferential statistics) versus effect sizes (descriptive statistics). In the current investigation, this debate assumes a rather distinctive form (Simonton, 1999c). Clearly, the sample was not randomly drawn from some indefinitely large population. On the contrary, the "sample", was deliberately selected to include all extent operas by all composers who have contributed at least one work to the standard operatic repertoire. As a necessary consequence, all descriptive statistics, such as correlation and regression coefficients, must represent the actual structural parameters for that well-de-

${ }^{3}$ In fact, the key substantive inferences are unchanged even if the expertise-acquisition variables are entered simultaneously with the 11 control variables rather than in the hierarchical design chosen here. The central conclusions are not contingent on the kind of analysis adopted. 
fined population. Inferential statistics per se are thereby irrelevant to making that generalization. To be sure, one might argue that there should be an interest in determining whether the results might be generalized to some hypothetical population beyond these 911 operas and 59 composers, such as all operas, all composers, or even all creative products and their creators. But this matter cannot be addressed by standard significance tests anyway because the cases were not randomly sampled from that larger population.

In fact, on logical grounds alone it can be inferred that the current sample cannot be representative of any other population but itself. On the one hand, any empirical findings cannot possibly be extended to all those composers who failed to produce successful operas. Indeed, just the severe variance truncation in the dependent variable alone would strongly attenuate any discovered associations. The correlations would have to approach zero, leading to the false conclusion that expertise acquisition has no relevance whatsoever. That was the very reason why the sample was restricted to creators whose successful acquisition of the requisite creative expertise was beyond the smallest shadow of doubt. On the other hand, the findings cannot be extended with confidence to all creative individuals who have achieved comparable distinction in some domain outside the opera house. There already exists ample evidence that the developmental antecedents of creativity are not identical across all domains, but rather show a more complex pattern of similarity and contrast (see, e.g., Simonton, 1977c, 1984a, 1992). Accordingly, whether the results can be generalized to other populations can only be evaluated by collecting data on those varied populations. Solely the direct comparison of the descriptive statistics will then decide whether the development of creative expertise operates in a similar fashion across all types of achievement (see also Ericsson, 1996a, for parallel examples in other talent domains).

Because the sample is equivalent to the target population, much greater stress will be placed on the effect sizes than on the significance tests, even though the hypothetical probability levels will still be reported (and used as a crude "rule of thumb" for discussing results). To be specific, the goal of the forthcoming statistical analyses is to describe as accurately as possible how expertise acquisition operates in this representative population of creative products. That is, the descriptive statistics must provide precise gauges of effect sizes (especially whether the associations are best described by linear or nonlinear functions and by additive or nonadditive effects). In contrast, no attempt whatsoever is made to ensure that the inferential statistics are equally accurate. This differential treatment of descriptive and inferential statistics is most conspicuous with respect to the standard assumption that the cases be statistically independent. This assumption may be violated in the current data set. First, the 911 operas are distributed across just 59 composers, producing something akin to a repeated-measures or cross-sectional time-series design (Simonton, 1977b). Second, sometimes operas come in 
sets, such as the four operas that make up Wagner's Ring Cycle or Verdi's last two operas based on William Shakespeare. In these instances, it might be expected that aesthetic success would be positively correlated across the linked cases. Yet it is also conceivable that contrast effects might introduce negative linkages as well. Thus, the success of Leoncavallo's La bohème was probably handicapped when Puccini's own La bohème appeared in the preceding year. The dependencies among the cases would therefore be extremely difficult to model with any simple scheme (e.g., first-order autoregressive disturbances in the regression equations; cf. Simonton, 1977b). Nonetheless, the assumption of statistical independence is only germane to the inferential statistics anyway (Johnson, 1984). Because estimates of the coefficients themselves are completely unbiased even in small samples, these indicators of effect size remain valid. And, needless to say, the descriptive statistics are perfectly unbiased when the sample equals the population, as holds in the current investigation. Indeed, under such circumstances the point estimates are logically equivalent to the population parameters, rendering the standard errors of the "estimated" coefficients exactly zero on a priori grounds. ${ }^{4}$

Because the descriptive statistics are so critical, the residuals from all multiple-regression analyses were scrutinized for the potential impact of highly influential cases (i.e., exceptional outliers with high leverage). At no time were cases identified whose omission would have yielded noticeably different conclusions. Hence, the statistical findings are truly descriptive of the entire sample rather than being distorted by a few extreme cases.

\section{Zero-Order and Semi-Partial Correlations}

Table 2 shows the correlations between the log-transformed and residualized indicators of aesthetic success and the linear and logarithmic measures of cumulative expertise. For the log-transformed impact measures, all correlations are significant. In the case of the three cumulative years measures, the associations are all positive and roughly the same order of magnitude, albeit the number of years since the first opera is somewhat more weakly correlated than the years since the first compositions and the first lessons. Moreover, for these last two indicators, the logarithmic function appears somewhat superior to the linear function, suggesting some diminishing returns. When we turn to the results for the residualized scores, almost all of these effects disappear, with the lone exception of the logarithmic function

${ }^{4}$ The position here taken is by no means arbitrary or unique. Darlington (1990, p. 110) identified the assumption of random sampling as well as those of homoscedasticity and normality, as "secondary" because "the damage done by violation of these assumptions can always be lessened by collecting a larger or more representative sample,', whereas the assumption of linearity is considered "primary" because "the damage done by nonlinearity can be undone only by reconceptualizing the entire model." Because the current sample is both very large and highly representative, the primary concern must be the linearity assumption. 
TABLE 2

Correlations between Aesthetic Success (Log-Transformed and Residualized) and Cumulative Expertise (Linear and Logarithmic Functions)

\begin{tabular}{|c|c|c|c|c|}
\hline \multirow[b]{2}{*}{ Type of expertise acquisition } & \multicolumn{2}{|c|}{ Log-transformed } & \multicolumn{2}{|c|}{ Residualized } \\
\hline & Linear & Logarithmic & Linear & Logarithmic \\
\hline \multicolumn{5}{|l|}{ Years accumulated since } \\
\hline First operas & $.07 *$ & $.07 *$ & .06 & .05 \\
\hline First compositions & $.11 * *$ & $.17 * * *$ & .06 & $.12 * * *$ \\
\hline First lessions & $.10 * *$ & $.12 * * *$ & .05 & .06 \\
\hline \multicolumn{5}{|l|}{ Cumulative number of } \\
\hline Opears: Specific genre & $-.18 * * *$ & $-.19 * * *$ & $-.11 * *$ & $-.13 * * *$ \\
\hline Operas: All genre & $-.18 * * *$ & $-.16^{* * *}$ & -.06 & -.06 \\
\hline All vocal compositions & $-.13 * * *$ & $-.08 *$ & -.02 & -.00 \\
\hline All compositions & $.10 * *$ & $.08^{*}$ & $.17 * * *$ & $.13 * * *$ \\
\hline
\end{tabular}

$$
\begin{gathered}
\text { Note. } N=911 . \\
* p<.05 . \\
* * p<.01 . \\
* * * p<.001 .
\end{gathered}
$$

for the number of years the composer had been composing at the time he conceived the given opera. Hence, once control is introduced for possible contaminating factors, only years of compositional experience matters, and then only according to a decelerating acquisition function. Especially striking is the fact that the number of years that a composer has been creating operas has virtually nothing to do with the quality of the works he conceives in that genre.

Of course, one can easily argue that the above expertise measures are very crude. Two composers might have been creating operas for the same number of years but contrast greatly regarding the number of operas actually created during that interval. Furthermore, they do not distinguish the type of operas or other compositions generated during a particular period. The cumulativecounts indicators may therefore provide a more precise idea about how acquired expertise relates to creativity. As the corresponding correlations in Table 2 indicate, the outcome is quite distinct. Of the four indicators, only the cumulative number of compositions has a consistent positive association for both log-transformed and residualized aesthetic success measures (with the linear functions having a slight advantage over the logarithmic functions). Otherwise the correlations are consistently negative, although in the case of all operas and all vocal compositions the correlations are not significant for the residualized indicator of aesthetic success. Most remarkable is the consistent negative association between the impact of an opera and the number of previous operas the composer had created in the same genre. Here the acquisition of a more specialized expertise tends to undermine creativity within that specialty. On the other hand, the acquisition of a generic expertise- 
whether gauged by years since first composition or the cumulative number of compositions - evidently makes a positive contribution to the creation of an operatic masterwork. Cross-training helps ameliorate the adverse effects of overtraining.

All of the linear effects explain only a small proportion of the variance in the differential success of the 911 operas. Judging from the squared correlation coefficients, no expertise-acquisition indicator accounts for as much as $4 \%$ of the variance, and most account for $1 \%$ or less. Yet these proportions may understate the magnitude of association if the true functions are nonmonotonic.

\section{Quadratic Trend Analyses}

The best method to verify whether the longitudinal trends are truly monotonic is to examine the second-order polynomials. Hence, the log-transformed and residualized measures of aesthetic success were separately regressed on these two variables in a hierarchical analysis (Darlington, 1990). That is, first the linear term was entered into the equation, followed by the quadratic term. Only if the latter added a significant increment to the explained variance was it concluded that the trend was best described by the second-order polynomial. The maximum (or minimum) point was determined using differential calculus. That is, if $y=a+b_{1} x+b_{2} x^{2}$, where $y$ is the criterion variable, $x$ the linear term, and $x^{2}$ the quadratic term, with $b_{1}$ and $b_{2}$ the corresponding unstandardized regression coefficients, then it can be shown that the maximum (or minimum) appears at $x=-0.5 b_{1} / b_{2}$. According to the second derivative, if $b_{2}>0$, this point marks a minimum, but a maximum if $b_{1}<0$. The degrees of freedom for the $t$ tests are 908 for all regression coefficients reported in this section.

For the log-transformed indicator of aesthetic success, linear functions were found for cumulative years engaged in opera composition, the cumulative number of total operas composed, and the cumulative number of vocal works composed. For these three indicators the linear trends in Table 2 still hold (i.e., positive, negative, and negative, respectively). Two other measures featured significant quadratic functions with negative regression coefficients: cumulative years since first compositions $(b=-0.00115, \beta=-.15, t=$ $4.31, p<.001)$ and cumulative years since first lessons $(b=-0.00067, \beta=$ $-.08, t=2.34, p<.05)$. Because the signs are negative but with positive linear components $(b=0.02363, \beta=.16, t=4.58, p<.001$, and $b=$ $0.0182, \beta=.12, t=3.50, p<.001$, respectively), these trends are singlepeaked inverted-backward-J functions with maxima at 37 and 47 years, respectively. That is, aesthetic success first increases with increases in these two variables, reaches a high point, and thereafter decreases, but not to the level observed at the zero-expertise level. Two other measures were nonmonotonic in the reverse direction: cumulative specific-genre operas $(b=$ 
0.00393, $\beta=.19, t=3.05, p<.01)$ and cumulative total compositions ( $b=0.00009, \beta=.13, t=2.67, p<.01)$, the former with a negative linear function $(b=-0.11934, \beta=-.34, t=5.49, p<.001)$ and the latter with a linear function close to zero $(b=0.00043, \beta=.01, t=0.11, p=.91)$. Hence, the first trend is described as a backward-J function with a trough at 20 genre-specific operas, the latter as a $U$ function with a trough at 24 total compositions.

The findings were similar for the residualized measure of aesthetic success, but with only three significant departures from the linear results reported in Table 2 . The cumulative number of years since first compositions has significant linear $(b=0.01469, \beta=.11, t=3.14, p<.01)$ and quadratic $(b=-0.00093, \beta=-.13, t=3.86, p<.001)$ terms, yielding another inverted-backward-J function with a peak at 35 years (rather than 37 ). For the cumulative number of genre-specific operas, the linear term was again negative $(b=-0.08987, \beta=-.28, t=4.54, p<.001)$ and the quadratic again positive $(b=0.00387, \beta=.21, t=3.30, p<.01)$, once more describing a backward-J curve with a trough at 17 genre-specific compositions (rather than 20). And for the cumulative number of total compositions, both linear $(b=0.00622, \beta=.09, t=1.78, p=.075)$ and quadratic $(b=0.00007$, $\beta=.12, t=2.43, p<.05)$ terms were positive, producing a low point at zero compositions (rather than 24).

Although the addition of the quadratic term often augmented the amount of variance explained, it is evident that the separate cumulative experiences still account for relatively little variation in aesthetic success. The quadratic polynomial for the cumulative number of genre-specific operas boasts the largest squared multiple correlations for both log-transformed $\left(R^{2}=.04\right)$ and residualized measures $\left(R^{2}=.02\right)$, and yet the percentage of variance explained ranges only between 2 and $4 \%$. Even worse, the longitudinal trend for this indicator is still dominated by the negative linear component, which seems inconsistent with the expertise-acquisition hypothesis. Overall, the more work a composer produces in a specific operatic genre, the worse those products become, with a minor turnaround after the composer has produced between 17 and 20 works within that genre.

\section{Multiple-Regression Analyses}

In the foregoing analyses, the seven indicators of cumulative experience were assessed piecemeal. It is possible that when all sources of expertise are combined, a much larger proportion of variance in aesthetic success will be accounted for. Of course, it could also be that the indicators share enough variance that gains in explanatory power may be minimal. Accordingly, the several indicators must be introduced into a single multiple-regression equation. Such integrated analyses were performed for both linear and logarithmic independent variables. 
Linear expertise measures. As is evident in Table 1, the seven measures are correlated sufficiently that there exists some danger of multicollinearity, albeit the large sample size lessens the problem considerably (especially since multicollinearity is a problem that primarily affects inferential statistics). The correlation between cumulative operas and vocal works is especially high (because many composers did not create many vocal compositions besides those operatic). In response, the linear and quadratic terms were first entered into the equation, and then the nonsignificant terms dropped one by one, in reverse order of effect size. Only those linear and quadratic terms were retained that had a significant contribution to the overall multiple correlation. The results are shown in Table 3, which gives the unstandardized partial regression coefficients (the $b s$ ), the standardized partial regression coefficients ( $\beta \mathrm{s})$, and the tolerances. The latter statistics indicate the proportion of variance in a given expertise development measure that is independent of the other expertise measures. In addition, the tolerance multiplied by the square of the standardized partial regression coefficient $\left(\beta^{2}\right)$ yields the squared semipartial correlation, an indicator of the proportion of variance in aesthetic success that can be uniquely attributed to that expertise-acquisition predictor. This is sometimes preferred over the standardized partial regression coefficient as an index of effect size (Darlington, 1990).

Almost all effects replicate across both log-transformed and residualized measures. This was true for the number of years accumulated since the first opera (both positive linear functions), the number of years accumulated since the first composition (both curvilinear inverted-U functions, with both peaks at 27 years), the number of specific-genre operas accumulated (both backward-J curves, with troughs at 20 and 18 operas, respectively), the number of all-genre operas accumulated (both backward-J curves, with troughs at 95 and 79 operas, respectively), ${ }^{5}$ and the number of vocal compositions accumulated (no effects whatsoever and hence omitted from the table altogether). On the other hand, the years accumulated since first lessons had a J-shaped relation with log-transformed success but a U-shaped relation with the residualized measure. Even so, their troughs remained close, namely 28 and 34 years, respectively. The only other discrepancy was that cumulative total compositions exhibited an inverted-backward-J curve for the log-transformed measure, but a linear positive curve for the residualized measure. But this difference is relatively minor, especially given that the quadratic component accounts for much less variance than does the linear component, placing the peak near the maximum value of the independent variable (i.e., at 195 compositions). In both cases, the dominant tendency is for the success

\footnotetext{
${ }^{5}$ These two low points should be qualified by the observation that only one composer produced sufficient operas to exhibit the turnaround, namely Offenbach. Hence, these might be idiosyncratic to that single composer. This is the only known instance in which the descriptive statistics must apply to only one member of the sample.
} 


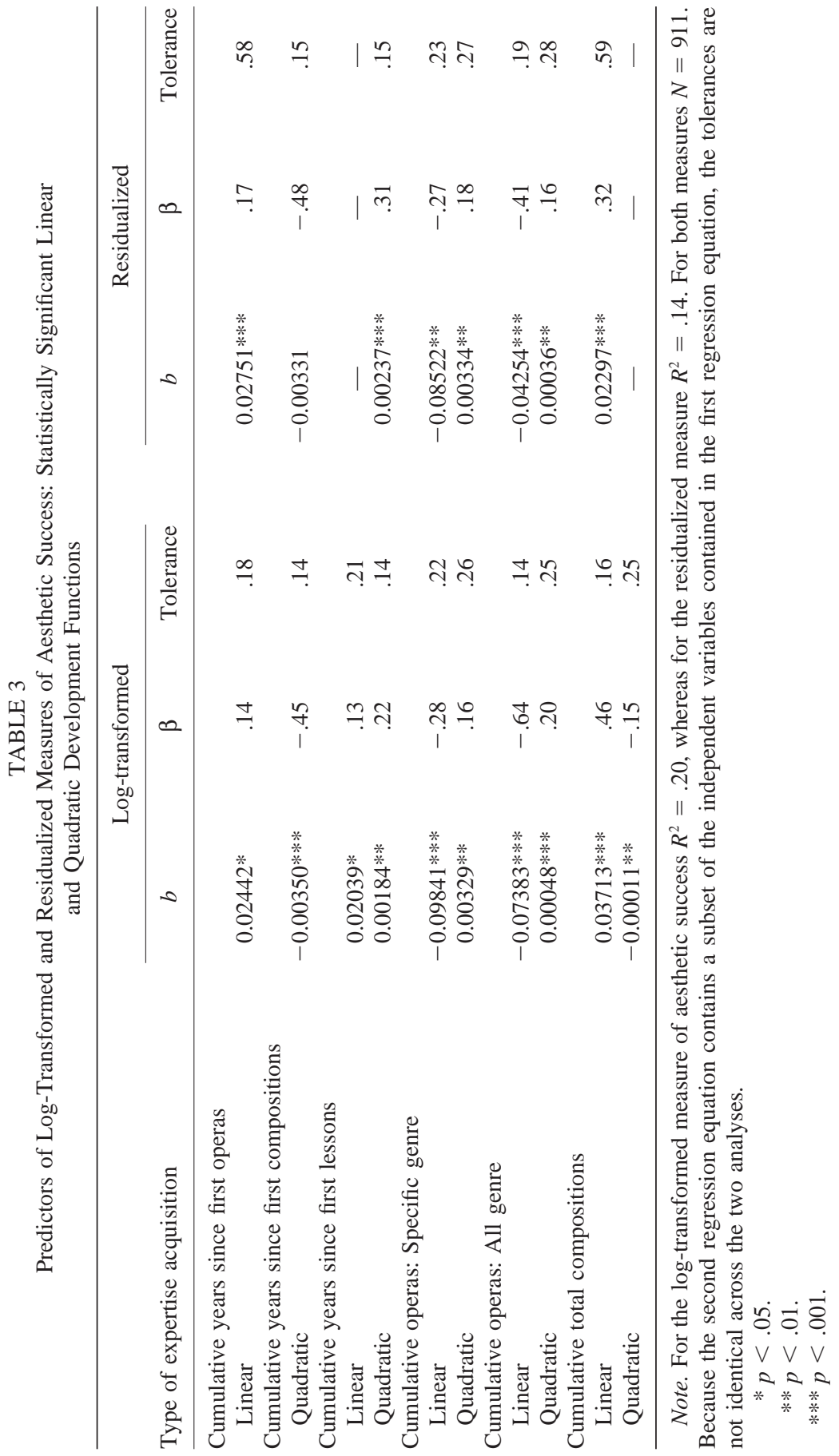


TABLE 4

Predictors of Log-Transformed and Residualized Measures of Aesthetic Success:

Statistically Significant Logarithmic Developmental Functions

\begin{tabular}{|c|c|c|c|c|c|}
\hline \multirow{2}{*}{$\begin{array}{l}\text { Type of expertise } \\
\text { acquisition }\end{array}$} & \multicolumn{2}{|c|}{ Log-transformed } & \multicolumn{2}{|c|}{ Residualized } & \multirow[b]{2}{*}{ Tolerance } \\
\hline & $b$ & $\beta$ & $b$ & $\beta$ & \\
\hline \multicolumn{6}{|l|}{ Years accumulated since } \\
\hline First operas & $0.61 * * *$ & .25 & $0.30 *$ & .14 & .24 \\
\hline First compositions & $0.63 * *$ & .20 & $0.56^{*}$ & .20 & .12 \\
\hline First lessions & $-0.77 *$ & -.17 & $-0.94 * *$ & -.23 & .13 \\
\hline \multicolumn{6}{|l|}{ Cumulative number of } \\
\hline Operas: Specific genre & $-0.30 * * *$ & -.14 & $-0.23 * *$ & -.12 & .72 \\
\hline Operas: All genre & $-1.20 * * *$ & -.58 & $-0.75 * * *$ & -.40 & .24 \\
\hline All compositions & $0.85 * * *$ & .39 & $0.79 * * *$ & .41 & .31 \\
\hline
\end{tabular}

Note. For the log-transformed measure of aesthetic success $R^{2}=.18$, whereas for the residualized measure $R^{2}=.11$. For both measures $N=911$. Because the two regression equations contain the exact same independent variables, the tolerances are unchanged across the two analyses.

$$
\begin{aligned}
* p & <.05 . \\
* * p & <.01 . \\
* * * & <.001 .
\end{aligned}
$$

of an operatic product to increase as a composer acquires more compositional experience in a diversity of musical forms, instrumental and vocal, concert and chamber.

Although the functions found in the multiple-regression analyses are very similar to those found in the earlier trend analyses, the results are not identical. A linear relation might become curvilinear once placed in a multiple-regression analysis, such as happened for the cumulative number of all operas, or a $\mathrm{J}$ curve might become an inverted $\mathrm{U}$, as occurred for cumulative years since first compositions. Nonetheless, most of these changes are relatively modest because the overall tendency remains largely unmodified. The linear and quadratic components will have the same signs, the shift in trends stemming from a small alteration in their relative magnitudes. Furthermore, several effects are virtually unaltered across the two data analyses, such as the linear positive effect of cumulative years since first opera.

Logarithmic measures. The log-transformed and residualized dependent variables were also regressed on the seven logarithmic measures. Again, the nonsignificant indicators were successively deleted in inverse order of effect size until only significant predictors remained in the equation. Table 4 presents the outcome.

Once more the results are comparable across both log-transformed and residualized dependent variables. Positive effects are found for years since first operas, years since first compositions, and the number of total composi- 
tions, no effects are found for the number of vocal compositions, and negative effects are found for years since first lessons and the number of operas, both specific and generic. The latter effects are somewhat problematic, however, from a theoretical standpoint. The logarithmic functions were first introduced to allow for a decelerating but still positive monotonic function-a trend still consistent with the expertise-acquisition hypothesis. Yet in three instances the curves are negative monotonic instead, in contradiction to expectation. It should also be noted that the total amount of variance explained in these two regression equations (18 and 11\%) are noticeably less than the two equations estimated in Table 3 . Hence, the logarithmic functions are less adequate both empirically and theoretically. Even so, it must be emphasized that the results in Tables 3 and 4 are fairly compatible. This is true because an inverted-backward- $J$ function is closely approximated by a positive logarithmic function, whereas a backward-J function is roughly approximated by a negative logarithmic function; the multiple correlations between quadratic and logarithmic functions are invariably in the $.90 \mathrm{~s}$, the missing nonmonotonic component accounting for almost all the discrepancy. Furthermore, both analyses concur when an expertise measure has no consequences (viz., the cumulative number of vocal compositions).

\section{Tests for Interaction Effects}

If the aim is to describe the acquisition of expertise within this significant sample, then two questions might be asked about whether the forgoing results hold for all operas and their composers or for just a subset. First, given that the compositions span nearly four centuries, do the same results hold for both earlier and later operas? Second, are the results as valid for the most prolific opera composers as for those who were least prolific? Because the logarithmic functions proved inadequate, the emphasis will be placed on testing whether the linear and quadratic terms given in Table 3 are invariant across the specified conditions. In each of the two tests, a zero-one dummy variable is first defined and then used to generate the appropriate interaction terms for both linear and quadratic functions (Darlington, 1990).

Earlier versus later works. The earliest opera in this study was composed in 1608, whereas the most recent was composed in 1988. It is obvious that the form has changed considerably in the intervening years, and some of these changes may affect the manner in which expertise acquisition operates. To test for the transhistorical invariance of the results, a dummy variable was defined that equaled 1 if the work was composed after the median year of 1865 , but equaled 0 if the work was composed on or before this date. Multiplying each of the independent variables listed in Table 3 by this dummy variable generated the product terms. The aesthetic success measures were then regressed on the original linear and quadratic terms, the dummy variable, and the several product terms (the increments to the squared multiple correlations always being statistically significant at the .01 level or bet- 
ter). According to this design, the regression coefficients for the main-effect variables describe the functions for the earlier works, whereas the coefficients for the interaction terms describe the difference in the functions between the earlier and later works. Consequently, when the product term is not significant, the same relationship holds across both earlier and later works. The degrees of freedom for these tests are 1 and 889 for the logtransformed measures and 1 and 893 for the residualized measure. The results were as follows:

1. For the log-transformed measure, the more recent works scored somewhat lower in aesthetic success than did the older works $(b=-0.60298$, $\beta=-.14, t=2.44, p<.05)$. In addition, there appeared two interaction effects. First, whereas accumulated years composing opera was strongly associated with aesthetic success for the earlier operas $(b=0.08397, \beta=.48$, $t=4.22, p<.001)$, this effect was reduced by about half the magnitude for the later operas $(b=-0.05450, \beta=-.23, t=2.10, p<.05)$. Second, the negative quadratic function for cumulative total compositions is not very substantial for the earlier works $(b=-0.00009, \beta=-.13, t=1.43, p>$ .1) but is far more substantial for the later works $(b=-0.00084, \beta=-.30$, $t=3.47, p<.001$ ), suggesting that the effect is mostly linear in the earlier period but highly curvilinear for the later period of opera composition.

2. For the residualized measure, the works composed after 1865 were again less aesthetically successful than those composed earlier $(b=$ $-0.62991, \beta=-.16, t=2.81, p<.01)$. Also as before, the positive repercussions of accumulative years of operatic composition remained substantial for the earlier operas $(b=0.05741, \beta=.36, t=5.23, p<.001)$, but the effect became more negligible for the later ones $(b=-0.04398, \beta=-.21$, $t=2.92, p<.01$ ). Hence, for some unknown reason, the number of years a composer has been writing operas is not been an important factor for more recent works. The only other interaction effect concerned the quadratic term for the cumulative number of years since first compositions. Although this curvilinear function is quite conspicuous for the earlier works $(b=$ $-0.00566, \beta=-.82, t=6.00, p<.001)$, it is much less so for the later works $(b=0.00324, \beta=.46, t=2.70, p<.01)$, albeit the function remains important for both periods.

All told, $80 \%$ of the developmental functions replicated for the log-transformed measure and $75 \%$ did so for the residualized measure. Moreover, the few departures from this overall transhistorical invariance were relatively minor, involving no more than the magnitude of effect changing from the earlier to later operas. For the most part, then, the relations between operatic creativity and the various measures of expertise acquisition have been fairly stable for nearly 4 centuries. This stability suggests that the reported findings capture some basic processes associated with creative development rather than being idiosyncratic to particular historical periods.

Prolific versus unprolific opera composers. Because the cross-sectional 
distribution of creative productivity in any given domain usually displays a strong right skew, a small percentage of the contributors account for a disproportionate number of the total contributions (for possible explanations, see Simonton, 1997, 1999b). Typically, the top 10th percentile in output is responsible for approximately half of the total contributions (e.g., Dennis, 1954a, 1954b). This inequality holds for opera as well, albeit not to quite so extreme a degree. Specifically, 457 of the 911 operas (or almost exactly $50 \%$ ) were created by just 11 of the 59 composers (or about 19\%), all of whom composed at least two dozen operas each (see footnote 1). Now it is conceivable that expertise acquisition may operate in a different manner for these highly prolific composers than holds for the remaining 48. For one thing, these individuals were clearly inclined to specialize in opera as the principal form of musical expression. It is very difficult to write many operas and at the same time make numerous contributions to other musical forms. So versatility should be minimized. In addition, it is more likely that these prolific composers were engaged in a certain amount of mass production, from time to time producing mere hackwork rather than attempting to offer their optimal creative performance. It is doubtful that such routinized output_- "just going through the motions" - would have the same consequences for expertise acquisition as would more serious attempts to produce genuine masterpieces. Accordingly, a zero-one dummy variable was defined that equaled 1 if the opera was composed by one of these highly prolific composers, but equaled 0 if otherwise. Once more, product terms were generated and then entered along with this dummy variable in the two regression equations shown in Table 3 . In short, the previously reported analysis was exactly replicated, but with the dummy variable coding prolific versus unprolific composers substituted for that coding earlier versus later composition dates. Hence, the degrees of freedom are the same for all tests (and the increments to the squared multiple correlations were again all significant at the .01 level or better). The outcome was as follows:

1. For the log-transformed measure, the prolific composers did not differ from the unprolific in terms of the overall aesthetic success of their operas $(b=0.57108, \beta=.13, t=1.58, p>.1)$. This outcome is consistent with the equal-odds rule that specifies quality of output to be a positive but probabilistic function of quantity of output (i.e., more hits means more misses; see Simonton, 1997). In addition, five interaction effects emerged. First, the positive consequence of cumulative years of opera composition that holds for the unprolific composers $(b=0.06532, \beta=.37, t=4.12, p<.001)$ reduced to virtual unimportance for the prolific composers $(b=-0.07052$, $\beta=-.26, t=2.56, p<.05)$. Evidently, when a creator writes so many opera scores, it matters very little how long he or she has been composing operas. Second, the negative quadratic function for cumulative years of general composition, while remaining important for the unprolific composers $(b=-0.00197, \beta=-.26, t=2.27, p<.05)$, is even more pronounced 
for the prolific composers $(b=-0.00330, \beta=-.26, t=2.55, p<.05)$. In other words, this nonmonotonic inverted-U relation accounts for more variance in aesthetic success for operas composed by prolific composers than for those operas composed by the unprolific. Third, the positive quadratic function for years accumulated since first lessons does not appear in the unprolific composers $(b=0.00020, \beta=.02, t=0.20, p>.5)$ but rather is confined to the prolific composers $(b=0.00362, \beta=.30, t=2.71, p<$ $.01)$. The last two interaction effects concern the cumulative number of total compositions. The linear term for that expertise-acquisition factor remains positive for the unprolific $(b=0.02873, \beta=.36, t=4.50, p<.001)$ and becomes even more so for the prolific $(b=0.07649, \beta=.56, t=2.76, p<$ $.01)$, whereas the quadratic term is only slightly negative for the first group $(b=-0.00005, \beta=-.07, t=1.15, p>.1)$ and extremely negative for the second $(b=-0.00143, \beta=-.48, t=2.31, p<.05)$. Hence, the invertedbackward-J curve for this predictor is most descriptive of the prolific composers.

2. For the residualized measure, there was again no main effect for the prolific-versus-unprolific dummy variable, in line with the equal-odds rule ( $b=0.48490, \beta=.12, t=1.59, p>.1$ ). Furthermore, only two interaction effects appeared, these both replicating what was found for the log-transformed measure. First, the negative quadratic function for cumulative years since the onset of composition, though remaining significant for the unprolific $(b=-0.00197, \beta=-.28, t=2.48, p<.05)$, becomes even more pronounced an effect for the prolific $(b=-0.00353, \beta=-.31, t=2.98$, $p<.01)$. Second, the positive quadratic function for cumulative years since the onset of first lessons, though now negligible for the unprolific ( $b=$ $0.00125, \beta=.16, t=1.38, p>.1)$, becomes even more prominent for the prolific $(b=0.00260, \beta=.24, t=2.14, p<.05)$. No interaction effects appeared for the variables involving the cumulative counts of compositions.

In sum, the acquisition of creative expertise operates in pretty much the same fashion across both prolific and unprolific composers. Most of the effects shown in Table 3 replicate across both groups (viz., 70\% for the logtransformed measure and $75 \%$ for the residualized measure). When a difference between the two classes of operatic composers does appear, it most often suggests that the effects are more potent for the prolific composers in the sample.

\section{DISCUSSION}

This is the very first investigation to assess systematically and comprehensively the association between cumulative domain-relevant experiences and the differential success of creative products. It is also the very first study to introduce multiple measures of expertise acquisition, including direct assessments of cumulative creative output in various forms and genre within the domain of achievement. Finally, it is the very first investigation to incorpo- 
rate explicit tests for nonmonotonic trends in the expertise-acquisition curves. Hence, this inquiry can be considered the first genuine test of the creative-expertise hypothesis. So how does that hypothesis look in light of the findings just reported?

In one respect, the results support the conclusion that domain-relevant experiences are an important factor behind creative achievement. As Table 3 indicates, between 14 and $20 \%$ of the aesthetic impact of a composer's opera can be predicted on the basis of cumulative experience within the domain of music. This degree of explanatory power is impressive when it is compared with previous results concerning the prediction of the differential success of creative products (see, e.g., Shadish, 1989; Simonton, 1980b, 1986b). Acquired domain expertise cannot be considered a negligible developmental influence. In fact, the predictors collectively account for almost as much variation in creative impact as do such variables as the composer's age, nationality, composition date, and various circumstances surrounding the opera's composition (see the Methods section for variables used to residualize the scores). Strengthening confidence all the more is the fact that more or less the same expertise-acquisition effects hold for both earlier and later operas and for both prolific and unprolific composers.

Even so, the prediction equations do not work the way that might be anticipated from prior studies of expertise acquisition. To appreciate why, it is necessary to return to the three critical questions raised at the beginning of this article. These questions concerned domain-specific experiences, domain specificity, and developmental trends. Taking these in reverse order, consider the following complications:

1. The developmental trends are seldom in line with expectation. Only in one case is aesthetic success a positive monotonic function of accumulated expertise: the longer the number of years a composer has been creating operas, the higher their aesthetic success tends to be. In contrast, all other expertise-acquisition measures display nonmonotonic functions-even after controlling for the general age curve. An excellent example is the number of years accumulated since the creator's first compositions, which bears an inverted-U relation with aesthetic success. In other words, there appears to be an optimum level of compositional experience that is most conducive to operatic creativity, which means that a creator can be composing too long to be maximally effective. Even more incompatible with a simple creativeexpertise explanation are the backward-J curves found for the cumulative number of operas, whether genre-specific or all operatic genres. Because the negative linear component dominates these trends, the implication is that increased expertise can often bring about decreased creativity. A sad illustration may be found in the career of Pietro Mascagni, whose best opera was his first (Cavalleria rusticana), his second best following next (L'amico Fritz), and thereafter his creativity gradually deteriorated until he began to be panned by critics and booed by audiences. 
2. It is somewhat surprising which types of domain-experiences seem to have the most utility for augmenting creative expertise. Although composers tend to write better operas if they have been composing operas for a longer time, the actual number of operas accumulated, as just noted, tends to have a detrimental effect. This runs counter to what holds for more traditional domains of expertise; it is not how long a pianist has been playing that is critical, but how much he or she has been practicing. Indeed, the most intriguing outcome is that the three cumulative years indicators all retained predictive power even after controlling for the cumulative number of operas and compositions. That is, given two creators with precisely the same number of prior operatic and nonoperatic works, the one who has been composing opera for the longer time has the higher likelihood of creating a great opera (a kind of distributed- rather than massed-practice effect). In creative domains there seems to be some benefits accrued simply from the sheer number of years that one has had the opportunity to contemplate the successes and failures of past contributions, however few the number of those contributions in the interim. Perhaps this suggests the long-term utility of extensive creative incubation between successive projects. Alternatively, this effect may indicate the advantage of waiting until more environmental feedback has been received before embarking on the next project.

3. Contrary to expectation, more domain-specific expertise does not invariably have more predictive power than more generic experiences. Years since first compositions and since first lessons account for more variance in aesthetic success than do the years since first operas. Although both measures of cumulative operatic production have strong effects, generic production is more potent as a predictor than is genre-specific production. In concrete terms, if a composer is working on an operetta, it is better to count the total number of operas he or she has so far created than to count the number of past operettas. Even worse, it might be better to count the total number of compositions of all types, for at least in that case the prediction would be in line with the expertise-acquisition hypothesis. The best operas tend to be written by those composers who have the most prolific in the creation of musical works. Just as curious is the fact that the cumulative number of vocal compositions, alone among the seven measures, has absolutely no relation with aesthetic success, whether positive or negative, linear or curvilinear. Yet it would certainly seem that vocal works have a more direct bearing on operatic creativity than do instrumental works.

Some of these unexpected findings might be explained by evoking the concepts of intellectual overtraining and cross-training. For example, the curvilinear, peaked functions found for cumulative years since first compositions might be seen as the consequences of overtraining, such as the decreased flexibility in the manner of approaching new compositional projects (Frensch \& Sternberg, 1989). Moreover, the predominantly negative functions found for the two cumulative opera measures and the positive function 
found for the cumulative compositions measure might reflect the advantage of cross-training. Nevertheless, some of the details of these longitudinal functions appear to defy easy interpretation. Probably the most perplexing are the backward-J curves for the two cumulative opera measures. Why should there appear an upturn at the upper extreme of the operatic experience distribution? It seems that if a composer specializes enough in just opera creation, an advantage is gained that partly compensates for the overtraining effect.

Although this $\mathrm{J}$ curve might be dismissed as some statistical fluke, there are at least three reasons why it should be taken seriously. First, the longitudinal trend is consistent across both specific and generic opera measures and across both log-transformed and residualized measures of aesthetic success (see Table 3). Second, the trend was estimated on a large and highly representative sample (i.e., all 911 extant operas by all 59 composers who contributed at least work to the standard repertoire). Third, a parallel result has been discovered by a different investigator using an entirely distinct data set. Sulloway (1996) found that the differential eminence of over 2000 scientists was a curvilinear J-shaped function of the number of different fields to which they made contributions. The most eminent were those who were either extremely specialized or extremely versatile, with the most eminent falling in the latter group. By the same token, the greatest operas tend to be written by those who specialize in writing operas (Rossini, Donizetti, Bizet, Wagner, Verdi, Puccini, etc.) or by those who show tremendous musical versatility (Mozart, Tchaikovsky, Richard Strauss, etc.), with the advantage favoring the latter composers. The only major contrast between these two findings, besides the domain of creativity, is the unit of analysis. The current results apply to the creative product, whereas Sulloway's results apply to the creative individual, but the same underlying developmental processes are probably operating in both cases. After all, the creativity of the individual is essentially the aggregate consequence of his or her lifetime output of separate creative products (Albert, 1975; Simonton, 1999a).

Obviously, more research must be carried out before we can fully understand the exact connection between expertise and creativity. Such empirical inquiries should proceed in two directions. The first direction concerns the manifest need to scrutinize other kinds of creative products besides those that fill the world's opera houses. These products might include other kinds of music, such as symphonies, as well as other types of aesthetic creativity, such as literature and the visual arts. Especially advantageous would be to compare more simple products, such as sonnets or songs, with more complex products, such as novels or symphonies. It would be equally desirable to look at scientific and technological products. To what degree is the citation rate for a particular journal article predictable from the scientist's cumulative publication record, whether articles, chapters, or books? To what extent is the commercial success of a patented invention determined by the inventor's 
prior experience creating devices in the same and different technological domains?

The second direction would be to expand the questions beyond the three that dominated the current study. Here the focus has been on how and what accumulated domain-relevant experiences contribute to exceptional performance. Yet, this is by no means the sole issue pertinent to probing the concept of creative expertise. Certainly one must predict that the very nature of a creative product - its very form and content attributes - should be partly determined by the specific pattern of experiences the creator has accumulated over the years. The strengths and weaknesses in the work should reflect to some detectable degree the creator's expertise profile.

To demonstrate the last point, I conducted an exploratory study on a subset of the operas in the present investigation $(N=192)$. Earlier it was discovered that the cumulative number of vocal compositions had no consequences on an opera's aesthetic success. But that experiential factor might still leave an imprint on the opera in other ways. Specifically, a composer who had more experience composing vocal music than instrumental music might produce operas that are more exceptional vocally than instrumentally (e.g., excellent arias, duets, trios, and choruses rather than overtures, intermezzi, preludes, and ballets). To test this conjecture, I first defined a variable that gauged the proportion of all famous melodies in an opera that were vocal (using Barlow \& Morgenstern, 1948, 1950; $M=0.82, S D=0.30$ ). Then I defined a second variable that assesses the proportion of all prior compositions that were vocal works (again using Gilder \& Port, 1978; $M=0.23, S D=0.28$ ). The correlation between these two variables is .22 $(p<.01)$. Hence, consistent with this corollary of the creative-expertise hypothesis, operas with a larger proportion of popular vocal music are indeed written by composers who have had proportionately more experience writing vocal music of all kinds. Comparable developmental effects may be identified in other domains of creative achievement.

Despite the fact that considerably more research must be done before the creativity-expertise nexus can be completely understood, I should close by noting a provocative implication of this line of inquiry. Toward the beginning of this article I observed a curious empirical finding about the nature of creative careers: The life of any creator is almost invariably an unpredictable succession of successes and failures, of hits and misses. A work that brings its creator unprecedented acclaim may be followed by an embarrassing fiasco. From the expertise-acquisition perspective, such dramatically uneven performance makes little or no sense. Yet if results like those found for opera are replicated for all other domains of creative achievement, the capricious quality of creative performance would become more easily understood. The impact of any given creative product would be a partial function of many prior experiences, both generic and specific, both cumulative years and cumulative products - and other expertise indices yet to be assessed. Moreover, 
each of these experiential factors will have their separate trends, whether linear or curvilinear, negative or positive, slopes steep or gradual or with peaks and troughs located at variable places during the course of the career. Accordingly, at any given time, the performance outcome for a particular work in a specified form or genre will be contingent on a chaotic mixture of influences, some beneficial and others deleterious. Rendering matters all the more unpredictable are the large number of personal and environmental factors that impinge on the creative process and thereby affect the quality of the final product (Cerulo, 1984; Simonton, 1980c, 1986a, 1986b, 1995). In this picture, only someone with almost infinite wisdom could figure out that the time is most ripe to conceive an experiment rather than a theory, to write a poem rather than a play, to paint a portrait rather than a landscape, or to compose a symphony rather than an opera. It is often noted that the creative individual has to fit the zeitgeist, or "spirit of the times."' The same necessity may hold for the very act of creation within the life of any creator. Ever vulnerable to this developmentally dynamic and personal "expertise zeitgeist," the creator must somehow generate the right product at the right place and at the right time.

\section{REFERENCES}

Albert, R. S. (1975). Toward a behavioral definition of genius. American Psychologist, 30, $140-151$.

Almquist, S. G. (1993). Opera mediagraphy: Video recordings and motion pictures. Westport, CT: Greenwood Press.

Arnheim, R. (1971). Art and visual perception: A psychology of the creative eye. Berkeley: Univ. of California Press.

Barlow, H., \& Morgenstern, S. (1948). A dictionary of musical themes. New York: Crown. Barlow, H., \& Morgenstern, S. (1950). A dictionary of vocal themes. New York: Crown.

Barron, F. X. (1969). Creative person and creative process. New York: Holt, Rinehart \& Winston.

Bauer, A. (1952). 150 Jahre Theater an der Wien. Zurich: Amalthea-Verlag.

Berlyne, D. (1971). Aesthetics and psychobiology. New York: Appleton-Century-Crofts.

Bloom, B. S. (Ed.). (1985). Developing talent in young people. New York: Ballantine Books.

Bloomfield, A. (1978). The San Francisco opera: 1922-1978. Sausalito, CA: Comstock Editions.

Blyth, A. (1994). Opera on CD: The essential guide to the best CD recordings of 100 operas (3rd ed.). London: Kyle Cathie.

Bontinck-Küffel, I. (1974). Opern auf Schallplatten 1900-1962: Ein historischer Katalog. Wien: Universal Edition.

Bramwell, B. S. (1948). Galton's "Hereditary", and the three following generations since 1869. Eugenics Review, 39, 146-153.

Celletti, R. (1976). Il teatro d'opera in disco. Milano: Rizzoli.

Cerulo, K. A. (1984). Social disruption and its effects on music: An empirical analysis. Social Forces, 62, 885-904. 
Cicchetti, D. V. (1991). The reliability of peer review for manuscript and grant submissions: A cross-disciplinary investigation. Behavioral and Brain Sciences, 14, 119-186.

Cole, S. (1983). The hierarchy of the sciences? American Journal of Sociology, 89, 111-139.

Cox, C. (1926). The early mental traits of three hundred geniuses. Stanford, CA: Stanford Univ. Press.

Csikszentmihalyi, M., Rathunde, K., \& Whalen, S. (1993). Talented teenagers: The roots of success and failure. Cambridge, England: Cambridge Univ. Press.

Darlington, R. B. (1990). Regression and linear models. New York: McGraw-Hill.

Dennis, W. (1954a). Bibliographies of eminent scientists. Scientific Monthly, 79, 180-183.

Dennis, W. (1954b). Productivity among American psychologists. American Psychologist, 9, $191-194$.

Dennis, W. (1966). Creative productivity between the ages of 20 and 80 years. Journal of Gerontology, 21, 1-8.

Digaetani, J. L. (1986). An invitation to the opera. New York: Facts on File.

Elo, A. E. (1965). Age changes in master chess performance. Journal of Gerontology, 20, 289-299.

Ericsson, K. A. (1996a). The acquisition of expert performance: An introduction to some of the issues. In K. A. Ericsson (Ed.), The road to expert performance: Empirical evidence from the arts and sciences, sports, and games (pp. 1-50). Mahwah, NJ: Erlbaum.

Ericsson, K. A. (Ed.). (1996b). The road to expert performance: Empirical evidence from the arts and sciences, sports, and games. Mahwah, NJ: Erlbaum.

Ericsson, K. A., \& Charness, N. (1994). Expert performance: Its structure and acquisition. American Psychologist, 49, 725-747.

Ericsson, K. A., Krampe, R. T., \& Tesch-Römer, C. (1993). The role of deliberate practice in the acquisition of expert performance. Psychological Review, 100, 363-406.

Faust, D. (1984). Limits of scientific reasoning. Minneapolis: Univ. of Minnesota Press.

Fawkes, R. (1986). Welsh National Opera. London: MacRae Books.

Feist, G. J. (1998). A meta-analysis of personality in scientific and artistic creativity. Personality and Social Psychology Review, 2, 290-309.

Fiske, S. T., \& Taylor, S. E. (1991). Social cognition (2nd ed.). New York: McGraw-Hill.

Freeman, J. W. (1984). The Metropolitan Opera stories of the great operas. New York: Norton.

Frensch, P. A., \& Sternberg, R. J. (1989). Expertise and intelligent thinking: When is it worse to know better? In R. J. Sternberg (Ed.), Advances in the psychology of human intelligence (Vol. 5, pp. 157-188). Hillsdale, NJ: Erlbaum.

Galton, F. (1869). Hereditary genius: An inquiry into its laws and consequences. London: Macmillan.

Gammond, P. (1979). The illustrated encyclopedia of recorded opera. New York: Harmony Books.

Gardner, H. (1993). Creating minds: An anatomy of creativity seen through the lives of Freud, Einstein, Picasso, Stravinsky, Eliot, Graham, and Gandhi. New York: Basic Books.

Gatti, C. (1964). Il teatro alla Scala: Nella storia e nell'arte (1778-1963). Milano: Ricordi.

Gilder, E., \& Port, J. G. (1978). The dictionary of composers and their music. New York: Ballantine.

Gough, H. G. (1979). A Creative Personality Scale for the Adjective Check List. Journal of Personality and Social Psychology, 37, 1398-1405.

Greenfield, E., Layton, R., \& March, I. (1993). The Penguin guide to opera on compact disc. London: Penguin. 
Grout, D J. (1988). A short history of opera (3rd ed.). New York: Columbia Univ. Press.

Gruber, H. E. (1974). Darwin on man: A psychological study of scientific creativity. New York: Dutton.

Hamilton, D. (Ed.) (1987). The Metropolitan Opera encyclopedia: A comprehensive guide to the world of opera. New York: Metropolitan Opera Guild.

Hamilton, M. (1990). A-Z of the opera. New York: Facts on File.

Harewood, Earl of (Ed.) (1994). The portable Kobbé's opera guide. New York: Perigee Books.

Hargens, L. L. (1978). Relations between work habits, research technologies, and eminence in science. Sociology of Work and Occupations, 5, 97-112.

Harlow, L. L., Mulaik, S. A., \& Steiger, J. H. (Eds.). (1997). What if there were no significance tests? Mahwah, NJ: Erlbaum.

Hayes, J. R. (1989). The complete problem solver (2nd ed.). Hillsdale, NJ: Erlbaum.

Headington, C., Westbrook, R., \& Barfoot, T. (1987). Opera: A history. London: Bodley Head.

Helson, R., \& Crutchfield, R. S. (1970). Mathematicians: The creative researcher and the average Ph.D. Journal of Consulting and Clinical Psychology, 34, 250-257.

Holden, A., Kennon, N., \& Walsh, S. (Eds.). (1993). The Viking opera guide on CD-ROM. London: Penguin.

Howe, M. J. A., Davidson, J. W., \& Sloboda, J. A. (1998). Innate talents: Reality or myth? Behavioral and Brain Sciences, 21, 399-442.

Hudson, L., \& Jacot, B. (1986). The outsider in science. In C. Bagley \& G. K. Verma (Eds.), Personality, cognition and values (pp. 3-23). London: Macmillan.

Johnston, J. (1984). Econometric methods (3rd ed.) New York: McGraw-Hill.

Kammann, R. (1966). Verbal complexity and preferences in poetry. Journal of Verbal Learning and Verbal Behavior, 5, 536-540.

Kahneman, D., Slovic, P., \& Tversky, A. (Eds.). (1982). Judgment under uncertainty: Heuristics and biases. Cambridge, England: Cambridge Univ. Press.

Krampe, R. T., \& Ericsson, K. A. (1996). Maintaining excellence: Deliberate practice and elite performance in young and older pianists. Journal of Experimental Psychology: General, 125, 331-359.

Kuhn, T. S. (1970). The structure of scientific revolutions (2nd ed.). Chicago: Univ. of Chicago Press.

Lehman, H. C. (1953). Age and achievement. Princeton, NJ: Princeton Univ. Press.

Lehman, H. C. (1962). More about age and achievement. Gerontologist, 2, 141-148.

Lindsey, D. (1988). Assessing precision in the manuscript review process: A little better than a dice roll. Scientometrics, $\mathbf{1 4}, 75-82$.

Lyons, J. (1968). Chronological age, professional age, and eminence in psychology. American Psychologist, 23, 371-374.

MacKinnon, D. W. (1978). In search of human effectiveness. Buffalo, NJ: Creative Education Foundation.

Manis, J. G. (1951). Some academic influences upon publication productivity. Social Forces, 29, 267-272.

Martindale, C. (1990). The clockwork muse: The predictability of artistic styles. New York: Basic Books.

Martindale, C., Brewer, W. F., Helson, R., Rosenberg, S., Simonton, D. K., Keeley, A., Leigh, J., \& Ohtsuka, K. (1988). Structure, theme, style, and reader response in Hungarian and American short stories. In C. Martindale (Ed.), Psychological approaches to the study of literary narratives (pp. 267-289). Hamburg: Buske. 
Martindale, C., \& Moore, K. (1989). Relationship of musical preference to collative, ecological, and psychophysical variables. Music Perception, 6, 431-446.

McDowell, J. M. (1982). Obsolescence of knowledge and career publication profiles: Some evidence of differences among fields in costs of interrupted careers. American Economic Review, 72, 752-768.

Meehl, P. (1954). Clinical versus statistical prediction: A theoretical analysis and a review of the evidence. Minneapolis: Univ. of Minnesota Press.

Morrison, D. E., \& Kenkel, R. E. (Eds.). (1970). The significance test controversy. Chicago: Aldine.

Ohlsson, S. (1992). The learning curve for writing books: Evidence from Professor Asimov. Psychological Science, 3, 380-382.

Osborne, C. (1983). The dictionary of opera. London: Macdonald.

Parker, R. (Ed.) (1994). The Oxford illustrated history of opera. Oxford: Oxford Univ. Press.

Pokorovsky, B. A., \& Grigorovich, Y. N. (1979). The Bolshoi: Opera and ballet at the greatest theater in Russia. New York: Morrow.

Quételet, A. (1968). A treatise on man and the development of his faculties. New York: Franklin. (Reprint of 1842 Edinburgh translation of 1835 French original)

Raskin, E. A. (1936). Comparison of scientific and literary ability: A biographical study of eminent scientists and men of letters of the nineteenth century. Journal of Abnormal and Social Psychology, 31, 20-35.

Roe, A. (1952). The making of a scientist. New York: Dodd, Mead.

Rohan, M. S. (Ed.). (1994). The classical video guide. London: Gollancz.

Root-Bernstein, R. S., Bernstein, M., \& Garnier, H. (1993). Identification of scientists making long-term, high-impact contributions, with notes on their methods of working. Creativity Research Journal, 6, 329-343.

Rostan, S. M. (1994). Problem finding, problem solving, and cognitive controls: An empirical investigation of critically acclaimed productivity. Creativity Research Journal, 7, 97110.

Rosenthal, H. (1958). Two centuries of operas at Covent Garden. London: Putnam.

Sadie, S. (Ed.). (1989). The new Grove handbooks in music: History of opera. London: Macmillan.

Sadie, S. (Ed.). (1996). The new Grove book of operas. New York: St. Martin's Press.

Schulz, R., \& Curnow, C. (1988). Peak performance and age among super athletes: Track and field, swimming, baseball, tennis, and golf. Journal of Gerontology, 43, 113-120.

Seifert, C. M., Meyer, D. E., Davidson, N., Patalano, A. L., \& Yaniv, I. (1995). Demystification of cognitive insight: Opportunistic assimilation and the prepared-mind perspective. In R. J. Sternberg \& J. E. Davidson (Eds.), The nature of insight (pp. 65-124). Cambridge, MA: MIT Press.

Shadish, W. R., Jr. (1989). The perception and evaluation of quality in science. In B. Gholson, W. R. Shadish, Jr., R. A. Neimeyer, \& A. C. Houts (Eds.), The psychology of science: Contributions to metascience (pp. 383-426). Cambridge: Cambridge University Press.

Simon, H. A., \& Chase, W. G. (1973). Skill in chess. American Scientist, 61, 394-403.

Simon, H. W. (1989). 100 great operas and their stories. New York: Anchor.

Simon, R. J. (1974). The work habits of eminent scientists. Sociology of Work and Occupations, 1, 327-335.

Simonton, D. K. (1976). Biographical determinants of achieved eminence: A multivariate approach to the Cox data. Journal of Personality and Social Psychology, 33, 218-226.

Simonton, D. K. (1977a). Creative productivity, age, and stress: A biographical time-series 
analysis of 10 classical composers. Journal of Personality and Social Psychology, 35, 791-804.

Simonton, D. K. (1977b). Cross-sectional time-series experiments: Some suggested statistical analyses. Psychological Bulletin, 84, 489-502.

Simonton, D. K. (1977c). Eminence, creativity, and geographic marginality: A recursive structural equation model. Journal of Personality and Social Psychology, 35, 805-816.

Simonton, D. K. (1980a). Land battles, generals, and armies: Individual and situational determinants of victory and casualties. Journal of Personality and Social Psychology, 38, 110119.

Simonton, D. K. (1980b). Thematic fame, melodic originality, and musical zeitgeist: A biographical and transhistorical content analysis. Journal of Personality and Social Psychology, 38, 972-983.

Simonton, D. K. (1980c). Thematic fame and melodic originality in classical music: A multivariate computer-content analysis. Journal of Personality, 48, 206-219.

Simonton, D. K. (1983). Formal education, eminence, and dogmatism: The curvilinear relationship. Journal of Creative Behavior, 17, 149-162.

Simonton, D. K. (1984a). Artistic creativity and interpersonal relationships across and within generations. Journal of Personality and Social Psychology, 46, 1273-1286.

Simonton, D. K. (1984b). Creative productivity and age: A mathematical model based on a two-step cognitive process. Developmental Review, 4, 77-111.

Simonton, D. K. (1984c). Is the marginality effect all that marginal? Social Studies of Science, 14, 621-622.

Simonton, D. K. (1985). Quality, quantity, and age: The careers of 10 distinguished psychologists. International Journal of Aging and Human Development, 21, 241-254.

Simonton, D. K. (1986a). Aesthetic success in classical music: A computer analysis of 1935 compositions. Empirical Studies of the Arts, 4, 1-17.

Simonton, D. K. (1986b). Popularity, content, and context in 37 Shakespeare plays. Poetics, 15, 493-510.

Simonton, D. K. (1987). Musical aesthetics and creativity in Beethoven: A computer analysis of 105 compositions. Empirical Studies of the Arts, 5, 87-104.

Simonton, D. K. (1988a). Age and outstanding achievement: What do we know after a century of research? Psychological Bulletin, 104, 251-267.

Simonton, D. K. (1989a). Age and creative productivity: Nonlinear estimation of an information-processing model. International Journal of Aging and Human Development, 29, 23 37.

Simonton, D. K. (1989b). The swan-song phenomenon: Last-works effects for 172 classical composers. Psychology and Aging, 4, 42-47.

Simonton, D. K. (1990). Lexical choices and aesthetic success: A computer content analysis of 154 Shakespeare sonnets. Computers and the Humanities, 24, 251-264.

Simonton, D. K. (1991a). Career landmarks in science: Individual differences and interdisciplinary contrasts. Developmental Psychology, 27, 119-130.

Simonton, D. K. (1991b). Emergence and realization of genius: The lives and works of 120 classical composers. Journal of Personality and Social Psychology, 61, 829-840.

Simonton, D. K. (1991c). Latent-variable models of posthumous reputation: A quest for Galton's G. Journal of Personality and Social Psychology, 60, 607-619.

Simonton, D. K. (1992). Leaders of American psychology, 1879-1967: Career development, creative output, and professional achievement. Journal of Personality and Social Psychology, 62, 5-17. 
Simonton, D. K. (1995). Drawing inferences from symphonic programs: Musical attributes versus listener attributions. Music Perception, 12, 307-322.

Simonton, D. K. (1996). Creative expertise: A life-span developmental perspective. In K. A. Ericsson (Ed.), The road to expert performance: Empirical evidence from the arts and sciences, sports, and games (pp. 227-253). Mahwah, NJ: Erlbaum.

Simonton, D. K. (1997). Creative productivity: A predictive and explanatory model of career trajectories and landmarks. Psychological Review, 104, 66-89.

Simonton, D. K. (1998). Fickle fashion versus immortal fame: Transhistorical assessments of creative products in the opera house. Journal of Personality and Social Psychology, 75, 198-210.

Simonton, D. K. (1999a). Origins of genius: Darwinian perspectives on creativity. New York: Oxford Univ. Press.

Simonton, D. K. (1999b). Talent and its development: An emergenic and epigenetic model. Psychological Review, 106, 435-457.

Simonton, D. K. (1999c). Significant samples: The psychological study of eminent individuals. Psychological Methods, 4, 425-451.

Smith, S. M. (1995). Fixation, incubation, and insight in memory and creative thinking. In S. M. Smith, T. B. Ward, \& R. A. Finke (Eds.), The creative cognition approach (pp. 136156). Cambridge, MA: MIT Press.

Sorokin, P. A. (1937-1941). Social and cultural dynamics (4 vols.). New York: American Book.

Steck, L., \& Machotka, P. (1975). Preference for musical complexity: Effects of context. Journal of Experimental Psychology: Human Perception and Performance, 104, 170174.

Sternberg, R. J., \& Gordeeva, T. (1996). The anatomy of impact: What makes an article influential? Psychological Science, 7, 69-75.

Sternberg, R. J., \& Lubart, T. I. (1995). Defying the crowd: Cultivating creativity in a culture of conformity. New York: Free Press.

Subotnik, R. F., \& Arnold, K. D. (Eds.). (1994). Beyond Terman: Contemporary longitudinal studies of giftedness and talent. Norwood, NJ: Ablex.

Sulloway, F. J. (1996). Born to rebel: Birth order, family dynamics, and creative lives. New York: Pantheon.

Tweney, R. D. (1990). Five questions for computationalists. In J. Shrager \& P. Langley (Eds.), Computational models of scientific discovery and theory information (pp. 471-484). San Mateo, CA: Kaufmann.

Walsh, T. J. (1986). Monte Carlo opera: 1910-1951. Kilkenny, Ireland: Boethius Press.

White, R. K. (1931). The versatility of genius. Journal of Social Psychology, 2, 460-489.

Winner, E. (1996). Gifted children: Myths and realities. New York: BasicBooks.

Vitz, P. C. (1964). Preferences for rates of information presented by sequences of tones. Journal of Experimental Psychology, 68, 176-183.

Zuckerman, H. (1977). Scientific elite. New York: Free Press.

Received: May 6, 1999 